\title{
Editorial
}

\section{The Changing Academy}

\section{KEITH ARCHER*}

The Canadian Journal of Higher Education has long been an instrument for examination of changes within the system of higher education. This role continues with the current issue, with a variety of articles on various aspects of change. These include studies on the manner in which the various professorial functions are integrated into the working lives of academics; student preparedness for postsecondary study and the related issue of changing 'standards'; the changing importance of the commercialization of university research and options for its implementation; demands and pressures for increased accountability; and the changing face of the professoriate, as women and other groups historically under-represented enter the professoriate in greater numbers. These changes reflect, in part, the changing realities of Canadian society and, in part, the new roles being cast for our universities. The trends discussed in these articles reflect only a portion of a broader set of changes that are profoundly reshaping the system of higher education. Indeed, the evidence suggests that the Canadian system of higher education in general, and the university system in particular, is being restructured. Furthermore, the system that emerges from this period of transformation, which likely will extend over the next decade, may be

* Keith Archer is an Associate editor of The Canadian Journal of Higher Education, and a member of the editorial team. He also is a Professor of Political Science, and Interim Vice-President (Research) at The University of Calgary. 
largely unrecognizable from the system of the last decade. It is our hope and desire that the pages of this issue of the Journal will play an important role as a forum for the discussion of these changes.

\section{Differentiation and Institutional Planning}

If one asked in 1990 what were the areas of strength or significance in research or teaching at a particular Canadian university, the answer given either by a faculty member or university administrator likely would be some variant of, "Why do you ask?", or "We're strong in all areas." There might also be a further dismissal of the question by reference to the fact that measuring excellence is very difficult, if not impossible. At best, many in the university community viewed discussions of research excellence as largely public relations exercises, intended to mollify federal, but mostly provincial, politicians and civil servants charged with overseeing the university system. One of the results of this aversion to identifying areas of strength was the development of a university system relatively undifferentiated by disciplinary focus and specialization. This is not to suggest there were no differences in the university system, as even the categorizations of a prominent magazine attest. It is to suggest, however, that among the 'doctoral' institutions, for example, there tended not to be strong disciplinary identities.

The transformation of the Canadian university system can best be understood as involving the twin engines of differentiation and institutional planning, both of which are fuelled by a major reinvestment of funds into the universities. The 1990s witnessed the first steps towards this increased differentiation, in part through the creation of the National Centres of Excellence program, by providing significant federal funds into creating areas of concentration across the research community. However, the Centres tend to function as an integrated web, linking researchers across geographical space by their disciplinary interests. Therefore, while the Centres often create multiple nodes of research strength, they also tend to cluster resources among a limited number of partner institutions and thereby lead to greater differences across the system.

The greatest impact, however, in the movement to increased differentiation and institutional planning initiated by the federal government 
has come through two major initiatives to rebuild Canada's intellectual infrastructure - the Canada Foundation for Innovation (CFI), and the Canada Research Chairs (CRC) programs. Together, these initiatives represent a direct investment of federal funds of approximately $\$ 3$ billion, and together with partnership funding required for their full implementation, will bring about $\$ 6$ billion in new funds into the universities.

The new era of institutional planning was initiated, inauspiciously, through the first CFI competition in 1998. Universities applying for Innovation awards from CFI were required to submit Institutional Research Plans (IRP) to support their applications. The plans were intended to demonstrate the way in which the various infrastructure awards would advance the overall research agenda of the university. Of course, this presupposed that institutions had overall research agendas, and furthermore, that there was an explicit linkage between the institutions' agendas and priorities and their capital infrastructure needs. In many instances, these assumptions were unwarranted. Furthermore, the situation was further complicated by the fact that, in the first round, CFI awards were limited to certain disciplinary areas - in particular, medicine, engineering, science and the environment. This limitation on the scope of CFI awards meant, of course, that in the preparation of the first round of research plans for CFI, universities had no incentive to include the social sciences, humanities, fine arts, or the professions. The IRP, however, was intended largely as a 'private' document for the CFI and its adjudication process, and therefore these potential problems could be overlooked by many.

By the second round of the CFI, in 2000, the terms of reference for the program were expanded to include all disciplines, and therefore all parts of a university's community tended to view it as more significant. Furthermore, it was not unusual for universities to put into place processes for identifying their strengths and institutional priorities, part of which may find reflection in requests for increased capital infrastructure, and part of which may be used for other resource allocation decisions. These trends were provided a very significant boost through the introduction of the CRC program, also in 2000. A key feature of the CRC program is that submissions for these chairs also requires the 
submission of an IRP, and further, that universities are encouraged to use the same IRP for both of these federal programs (CFI and CRC). To increase the salience of these plans, the CRC secretariat announced the intention to publish abbreviated versions of IRPs.

The requirement for publicized institutional research plans, tied very closely to requests for capital infrastructure and new high-profile faculty appointments, can be expected inevitably to lead to increased differentiation among Canadian universities. It will soon become apparent, if it is not so already, that identifying areas of research strength and focus means, by implication, that other areas are not being so identified by any given university. As well, over time one might expect that the various universities will identify the areas in which they enjoy a comparative advantage, due to any variety of factors, such as natural endowments, fortuitous faculty hiring at earlier points in time, priorities of the provincial or local communities, and other such factors. With new resources to commit to supporting areas of strategic focus, and documents that circulate globally as to the university's strengths and aspirations, adjustments appear inevitable. And the adjustments will lead to greater differentiation among universities.

It also can be expected that provincial governments will play an increasingly active role in supporting universities to move in directions that correspond with provincial objectives. Although not all provinces have increased support to the university system in proportion to federal initiatives, many have recently reinvested or have given indications that reinvestment will be forthcoming. Provincial reinvestment has tended to share at least one feature with increased federal funds, and that is it tends to be highly targeted. For example, at the federal level, CFI awards have been heavily weighted towards science, engineering and health research and against research in the social sciences, humanities and the professions. Likewise, the CRC program allocates $45 \%$ of chairs based on NSERC success, $35 \%$ on CIHR success and $20 \%$ on SSHRC success.

At the provincial level, the funding is increasingly targeted as well. Whereas in 1990 adjustments to university funding from the province typically came in the form of adjustments to the base operating budget, today they tend to be in the form of a restricted grant, to be used for 
specific purposes. More often than not, the additional funds are to support research and scholarship in areas that are most likely to have benefits for the province's economic strategy. This is the hub of the issue. As governments increasingly see the role of universities as being an essential partner in an economic development strategy, university communities will be well served to reflect on the implications of this for their broader mission to society. Indeed, as funds increasingly come into universities for targeted areas of research, and in some provinces, in targeted areas of growth in undergraduate teaching, universities become less autonomous in shaping their future. In this way, the very essence of the university is transformed.

This issue of The Canadian Journal of Higher Education begins to touch on some of these changes in the university system. We feel there is much more to be said on these topics. As an editorial team, we are considering providing future special issues on a number of topics, and you will see in this issue of the Journal a call for papers on the theme of internationalization. We are also considering a further special issue on transformation of the university, and would encourage your feedback on this and other topics. 